\title{
Insights into Enhanced Oil Recovery by Polymer-Viscosity Reducing Surfactant Combination Flooding in Conventional Heavy Oil Reservoir
}

\author{
Yuqiu Chen, ${ }^{1}$ Hong He ${ }^{D},{ }^{1}$ Qun Yu, ${ }^{2}$ Huan Liu, ${ }^{1}$ Lijun Chen, ${ }^{1}$ Xiaorui Ma, \\ and Wenzheng Liu ${ }^{1}$ \\ ${ }^{1}$ College of Petroleum Engineering, Yangtze University, Wuhan 430100, China \\ ${ }^{2}$ Research Institute of Exploration and Development of Shengli Oilfield, SINOPEC, Dongying 257000, China \\ Correspondence should be addressed to Hong He; hehong1103@163.com
}

Received 8 April 2021; Accepted 13 May 2021; Published 24 May 2021

Academic Editor: Xiaofei Sun

Copyright (C) 2021 Yuqiu Chen et al. This is an open access article distributed under the Creative Commons Attribution License, which permits unrestricted use, distribution, and reproduction in any medium, provided the original work is properly cited.

\begin{abstract}
Polymer flooding has a significant potential to enhance oil recovery in a light oil reservoir. However, for polymer flooding in a conventional heavy oil reservoir, due to unfavorable mobility ratio between water and oil, the improvement of sweep efficiency is limited, resulting in a low incremental oil recovery and failure to achieve high-efficiency development for polymer flooding in a conventional heavy oil reservoir. Inspired by the EOR mechanisms of the surfactant-polymer (SP) flooding process, the polymer-viscosity reducing surfactant flooding (P-VRSF) system was proposed to enhance conventional heavy oil recovery. Thus, to gain an insight into enhancing oil recovery by P-VRSF in a conventional heavy oil reservoir, the viscosity property, oilwater interfacial tension property, and oil viscosity reduction property were investigated. A series of parallel sand pack experiments were conducted to investigate enhanced oil recovery ability of polymer flooding and P-VRSF in a heterogeneous reservoir. Then, the $2 \mathrm{D}$ micromodel flooding experiments were conducted to investigate the EOR mechanism from porous media to pore level. Results demonstrated that polymer could increase the viscosity of injection water and improve the sweep efficiency. The emulsifying stability of surfactant with ultralow IFT $\left(10^{-3} \mathrm{mN} / \mathrm{m}\right)$ was worse than that of the surfactant with higher IFT $\left(10^{-2} \mathrm{mN} / \mathrm{m}\right)$. The viscosity reduction rate of the surfactant with higher IFT was higher than $80 \%$ at different oilwater volume ratios. The incremental oi recovery of P-VRSF was higher than that of polymer flooding. Moreover, the polymerviscosity reducing surfactant with higher IFT could have higher incremental oil recovery. The $2 \mathrm{D}$ micromodel flooding results showed that the swept area of polymer flooding and P-VRSF was larger than that of water flooding. Moreover, the swept area of the surfactant with good emulsifying stability was larger than that of the surfactant with ultralow IFT. These findings could provide insights into enhancing oil recovery by P-VRSF in the conventional heavy oil reservoir.
\end{abstract}

\section{Introduction}

With decreasing conventional light oil reserves, unconventional resources have becoming more and more important for meeting the increasing demand of crude oil. Heavy oil resources as one of the most important unconventional resources are widely distributed in several countries such as China, Canada, and Venezuela. The viscosity of heavy oil typically ranges from 50 to $50000 \mathrm{mPa} \cdot \mathrm{s}$ at reservoir temperature and pressure [1-5]. Water flooding is recognized as one of the most common secondary oil recovery techniques after primary production period, which has been widely applied for the recovery of light oil. However, for heavy oil reservoirs, due to adverse mobility ratio of injection water and crude oil, the fingering effect and water breakthrough occur. It has been reported that the recovery of heavy oil reservoirs developed by conventional water flooding is only about $5 \% \sim 10 \%$ of the original oil in place. Hence, water flooding is more suitable for light or less viscous oil flooding than for heavy oil. In order to recover more heavy oil after conventional water flooding, different enhanced oil recovery (EOR) techniques including thermal oil recovery techniques and nonthermal 
techniques have been investigated [6-11]. The EOR processes focus on the reduction of oil viscosity or improvement of injection water viscosity, which can improve the mobility ratio of injection water and crude oil and enlarge sweep efficiency. On the other hand, the EOR processes focus on the reduction of oil-water interfacial tension and thereby reduction of the residual oil saturation, which can improve oil displacement efficiency.

Thermal oil recovery techniques including steam injection, steam huff and puff, and steam-assisted gravity drainage (SAGD) have been usually employed and proven to be efficient in many heavy oil reservoirs [12-14]. Compared with other thermal recovery methods, the SAGD provides more efficient recovery of unconventional oil resources, such as heavy oil and bitumen. However, for the deep and thin reservoirs, the SAGD or other thermal methods are economically nonprofitable. The severe heat loss during injection and high consumption of energy and water to generate steam can lead to nonprofitable and environmental concerns. Therefore, nonthermal recovery methods such as chemical enhanced oil recovery (EOR) methods are more promising methods for recovery of heavy oil in recent years [15-18].

Chemical enhanced oil recovery (EOR) methods are usually categorized as polymer flooding, surfactant-polymer (SP) flooding, and alkali-surfactant-polymer (ASP) flooding. By increasing the viscosity of the injection water and improving the mobility ratio, polymer flooding can improve sweep efficiency and thereby enhance oil recovery. Polymer flooding technology has been considered and implemented in many heavy oil reservoirs [19-30]. Although ASP flooding process has been implemented in fewer heavy oil reservoirs, the incremental oil recovery of ASP flooding is higher than that of polymer flooding. The surfactant can reduce the oilwater interfacial tension and thereby reduce the residual oil saturation and improve oil displacement efficiency. Adding an alkaline agent such as $\mathrm{NaOH}$ can promote the formation of in situ surfactant and reduce oil-water interfacial tension. Moreover, adding alkali can contribute to in situ formation of emulsion, which can improve mobility ratio due to the resistance factor during transport in porous media. However, the alkali in the ASP flooding system can cause some problems, which can restrict the application of ASP flooding. The alkali can react with rock mineral to cause severe scaling problems and promote the formation of water-in-oil $(\mathrm{W} / \mathrm{O})$ emulsion in the produced liquids that is too stable to be broken [31-44]. In addition, the high consumption of alkali for the heavy oil with low acid number, which will lead to saltsensitive effect and reduce the viscosity. Thus, due to the existence problems of severe scale formation and disposal of produced emulsions, surfactant-polymer (SP) flooding has gained more interests for enhancing oil recovery in recent years [45-50]. In fact, SP flooding pilots have been performed and proven to be efficient in many light oil reservoirs. While for heavy oil reservoirs, SP flooding has received much less attention. The EOR mechanism of SP flooding for light oil reservoirs includes mobility ratio improvement, ultralow interfacial tension, emulsification, and wettability alteration. Similarly, the mechanism of ultralow interfacial tension has also been suggested for the recovery of heavy oil. In recent
TABLE 1: The ionic composition and concentration of formation brine.

\begin{tabular}{lccccc}
\hline Ionic composition & $\mathrm{Na}^{+}$ & $\mathrm{Ca}^{2+}$ & $\mathrm{Mg}^{2+}$ & $\mathrm{Cl}^{-}$ & $\mathrm{HCO}_{3}{ }^{-}$ \\
\hline Concentration $\left(\mathrm{mg} \cdot \mathrm{L}^{-1}\right)$ & 3667 & 292 & 65 & 6056 & 527 \\
\hline
\end{tabular}

years, the mechanism of in situ formation of oil-in-water emulsion has been more focused and investigated to recover heavy oil. It is believed that viscous oil is difficult to displace and the adverse mobility ratio of water and oil is the dominant reason that governs the low incremental oil recovery. It has been reported that the in situ formation of emulsion can improve the mobility ratio and enlarge the sweep efficiency. Firstly, the in situ formation of oil-in-water (O/W) emulsion can reduce the viscosity of heavy oil and make it easier to flow in the reservoir. Secondly, the formed O/W emulsion can plug rock pores and improve sweep efficiency.

Thus, inspired by the EOR mechanisms of SP flooding process, the polymer-viscosity reducing surfactant flooding (P-VRSF) system that was composed of viscosity reducing surfactant and polymer was proposed to enhance conventional heavy oil recovery. To gain an insight into enhancing oil recovery by P-VRSF in the conventional heavy oil reservoir, the viscosity property, oil-water interfacial tension property, and oil viscosity reduction property were investigated. Then, a series of parallel sand pack experiments were conducted to investigate the enhanced oil recovery ability of polymer flooding and P-VRSF in heterogeneous reservoir. The 2D micromodel flooding experiments were conducted to investigate the EOR mechanism from porous media to pore level. We hope these findings will contribute to new insights into recovering heavy oil by P-VRSF.

\section{Materials and Methods}

2.1. Materials. The polymer used in this study was partially hydrolyzed polyacrylamide (HPAM) with molecular weight of $2.0 \times 10^{7}$ and hydrolysis degree of $24 \%$. The viscosity reducing surfactants used in this study were nonionic surfactants (A1 and D1) provided by Shengli oilfield. The density and viscosity of heavy oil obtained from Shengli oilfield are $0.956 \mathrm{~g} \cdot \mathrm{cm}^{-3}$ and $680 \mathrm{mPa} \cdot \mathrm{s}$, respectively. The ionic composition and concentration of simulated formation brine with TDS of $10607 \mathrm{mg} \cdot \mathrm{L}^{-1}$ were listed in Table 1.

\subsection{Methods}

2.2.1. Bulk Solution Preparation. The polymer solution was prepared by slowly adding polymer powder into the simulated formation brine under mechanical stirring at room temperature. The polymer solution was stirred for $12.0 \mathrm{~h}$ until it became completely transparent. After the polymer solution was prepared, the viscosity reducing surfactant was added into the polymer solution under mechanical stirring to obtain the combination system.

2.2.2. Viscosity Property Measurement. The viscosity property of polymer solution was measured by using the Brookfield DV-II viscometer. In this study, all the viscosity properties 


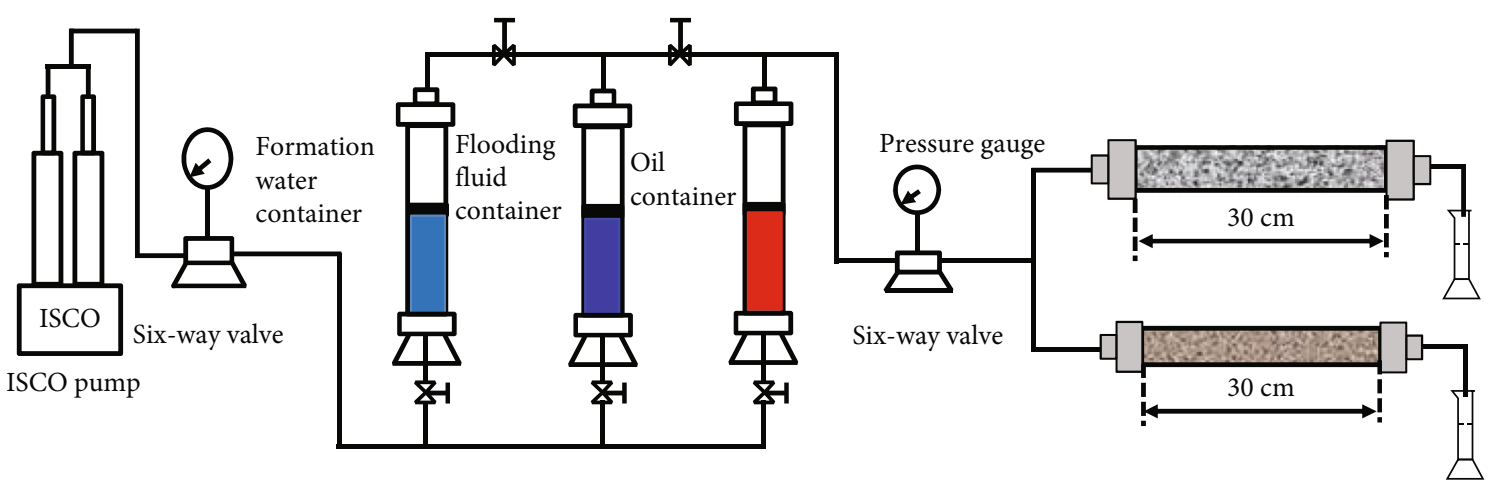

FIGURE 1: The schematic diagram of parallel sand pack flooding experimental apparatus.

TABLE 2: The porosity and permeability of sand packs used for flooding experiments.

\begin{tabular}{|c|c|c|c|c|}
\hline Test no. & Chemical slug & Sand packs & Permeability $\left(\mu \mathrm{m}^{2}\right)$ & Porosity $(\%)$ \\
\hline \multirow{2}{*}{$1 \#$} & \multirow{2}{*}{ Polymer flooding $(\mathrm{P})$} & High permeability & 3.64 & 42.1 \\
\hline & & Low permeability & 0.91 & 35.6 \\
\hline \multirow{2}{*}{ 2\# } & \multirow{2}{*}{ Polymer-viscosity reducing surfactant D1 flooding $(\mathrm{P}+\mathrm{D} 1)$} & High permeability & 3.97 & 41.4 \\
\hline & & Low permeability & 1.18 & 36.5 \\
\hline \multirow{2}{*}{ 3\# } & \multirow{2}{*}{ Polymer-viscosity reducing surfactant A1 flooding (P+A1) } & High permeability & 4.21 & 41.2 \\
\hline & & Low permeability & 1.25 & 38.7 \\
\hline
\end{tabular}

of polymer solution were measured under the shear rate of $7.34 \mathrm{~s}^{-1}$ at $70^{\circ} \mathrm{C}$.

2.2.3. Oil-Water Interfacial Tension Measurement. The oilwater interfacial tension between viscosity reduction surfactant with different concentrations and crude oil was measured by the spinning drop method on the apparatus of spinning drop interfacial tension meter TX 500C at simulated reservoir temperature of $70^{\circ} \mathrm{C}$.

(1) Emulsifying Stability and Viscosity Reducing Ability Evaluation. The emulsifying stability and viscosity reducing ability of surfactant are essential for recovering heavy oil. The experimental procedures of emulsifying stability evaluation were as follows: (1) After the viscosity reducing surfactant was prepared, according to the water-oil ratio, different viscosity reducing surfactant-heavy oil mixtures were prepared and placed in the oven at $70^{\circ} \mathrm{C}$ for $2.0 \mathrm{~h}$. (2) Then, the viscosity reducing surfactant-heavy oil mixtures were stirred by a homogenizer to form $\mathrm{O} / \mathrm{W}$ emulsion. (3) The formed emulsion was placed in the oven at $70^{\circ} \mathrm{C}$, and the water separating volume was recorded and the water separating proportion was calculated according to the following equation:

$$
f_{1}=\frac{V_{w}}{V_{0}},
$$

where $f_{1}$ is the water separating proportion, $\% ; V_{w}$ is the water separating volume, $\mathrm{mL}$; and $V_{0}$ is the initial water volume, mL.

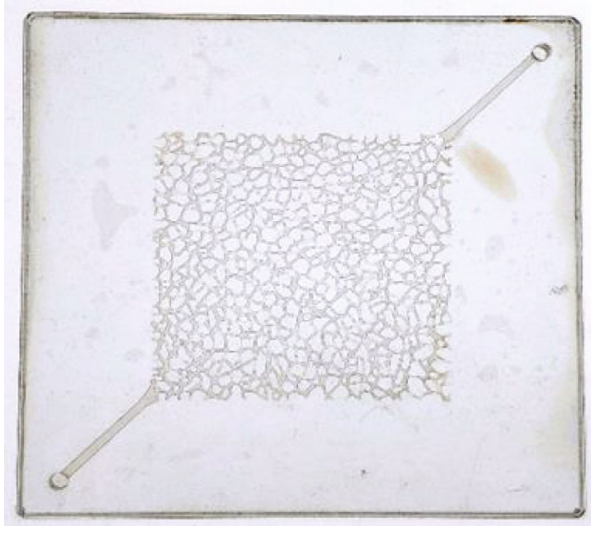

FIgURE 2: The appearance of 2D glass-etched micromodel.

The viscosity reducing ability of the surfactant was evaluated by viscosity reduction rate. The experimental procedures were as follows: (1) After the viscosity reducing surfactant was prepared, according to the water-oil ratio, different viscosity reducing surfactant-heavy oil mixtures were prepared and placed in the oven for $2.0 \mathrm{~h}$. (2) Then, the viscosity reducing surfactant-heavy oil mixtures were stirred by a homogenizer to form $\mathrm{O} / \mathrm{W}$ emulsion. (3) The viscosities of heavy oil and formed $\mathrm{O} / \mathrm{W}$ emulsion were measured using the Brookfield DV-II viscometer. (4) The viscosity reduction rates under different oil-water ratios were calculated according to the following equation:

$$
f_{2}=\frac{\mu_{0}-\mu}{\mu_{0}}
$$




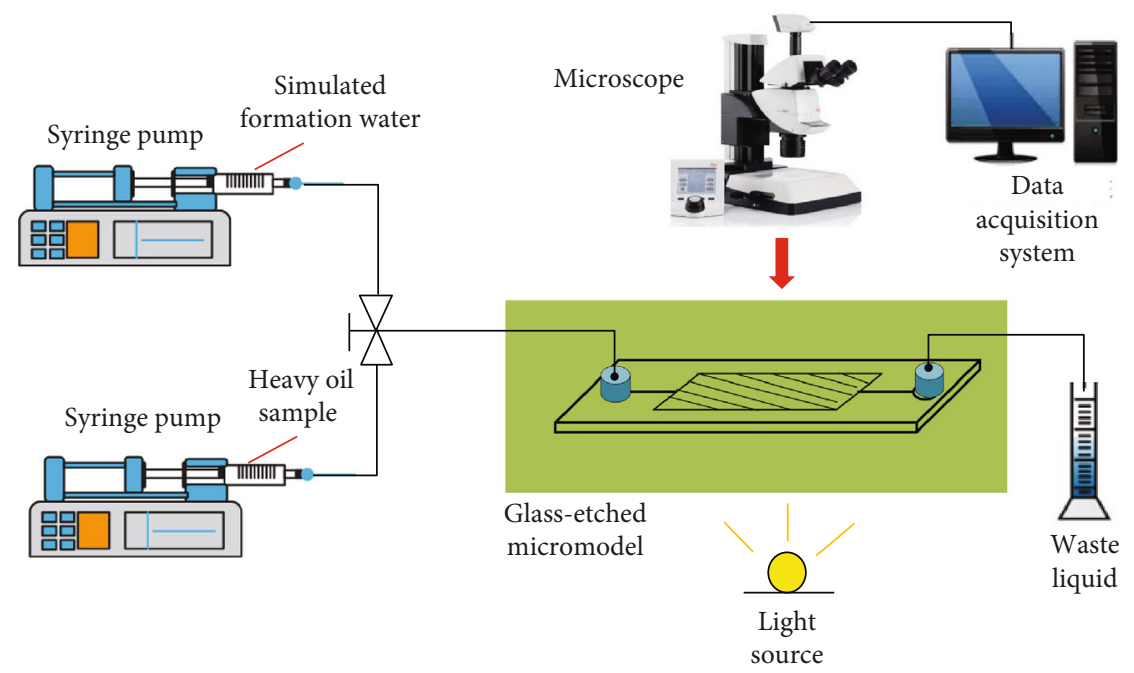

Figure 3: The schematic diagram of micromodel flooding experimental apparatus.

where $f_{2}$ is viscosity reduction rate, $\%$; $\mu_{0}$ is the viscosity of heavy oil, $\mathrm{mPa} \cdot \mathrm{s}$; and $\mu$ is the viscosity of emulsion after adding viscosity reducing surfactant, $\mathrm{mPa} \cdot \mathrm{s}$.

2.2.4. Parallel Sand Pack Flooding Experiment. To simulate the reservoir heterogeneity, it should be the parallel sand pack model that was composed of high- and lowpermeability sand packs $(\Phi 2.5 \mathrm{~cm} \times 30 \mathrm{~cm})$ was used in this study. Then, a series of parallel sand pack flooding experiments were conducted to evaluate the EOR ability of polymer flooding and P-VRSF. Figure 1 showed the schematic diagram of parallel sand pack flooding experimental apparatus.

The experimental procedures of sand pack flooding were as follows: (1) Sand pack preparation and basic properties measurement: the high- and low-permeability sand packs $(\Phi 2.5 \mathrm{~cm} \times 30 \mathrm{~cm})$ were prepared by adding different sizes of quartz sand and formation brine under vibration. Then, water flooding was conducted and the permeability of sand pack was measured by Darcy's law. (2) Crude oil saturation period: the wet-packed sand pack was flooded with crude oil until no water production. (3) Initial water flooding period: then, initial water flooding was conducted until the water cut reached 95\%. (4) Chemical flooding and subsequent water flooding period: then, $0.4 \mathrm{PV}$ chemical slug was injected into the sand packs and followed by subsequent water flooding until the water cut reached $98 \%$. Then, the flooding experiments were terminated. The injection pressure, volume of produced water, and oil were recorded during initial water flooding period, chemical flooding, and subsequent water flooding period. Table 2 showed the porosity and permeability properties of sand packs used for flooding experiments.

\subsubsection{The 2D Glass-Etched Micromodel Flooding Experiment.} To grasp a better understanding on the enhanced oil recovery mechanism of polymer-viscosity reducing surfactant combination flooding, the 2D glass-etched micromodel flooding experiments were performed. The transparent micromodel was used as the porous media. The glass-etched micromodel

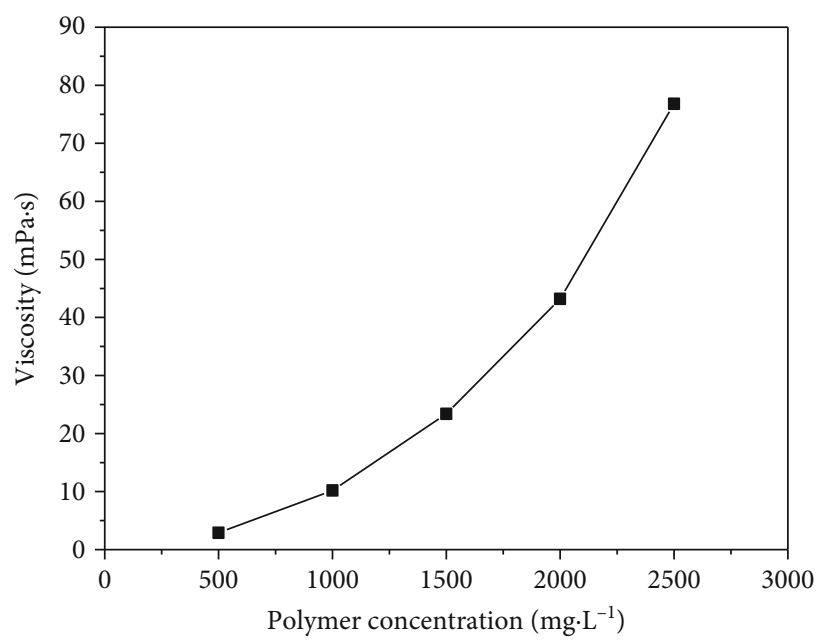

FIgURE 4: The viscosity of polymer solution versus polymer concentration.

was composed of two glass plates including the etched plate and cover plate, which were attached together and sealed to form an enclosed pore space. The etched plate was designed as heterogeneous pore size distribution. The micromodel pattern was shown in Figure 2. The size of the micromodel is $4 \mathrm{~cm} \times 4 \mathrm{~cm}$.

Figure 3 showed the experimental setup used to preform micromodel flooding experiments. The $2 \mathrm{D}$ visualization experimental apparatus is composed of transparent glassetched micromodel, high precise syringe pump, LED light source, high-resolution camera, and image acquisition and processing system. The high-resolution camera is used to record the fluids flow through the glass micromodel at different flooding stages. The image acquisition and processing system can be used to analyze the remaining oil saturation at different flooding stages.

Before each flooding test, the glass-etched micromodel was cleaned using toluene, ethanol, and deionized water. The experimental procedures of micromodel flooding were as follows: (1) The glass-etched micromodel was saturated 


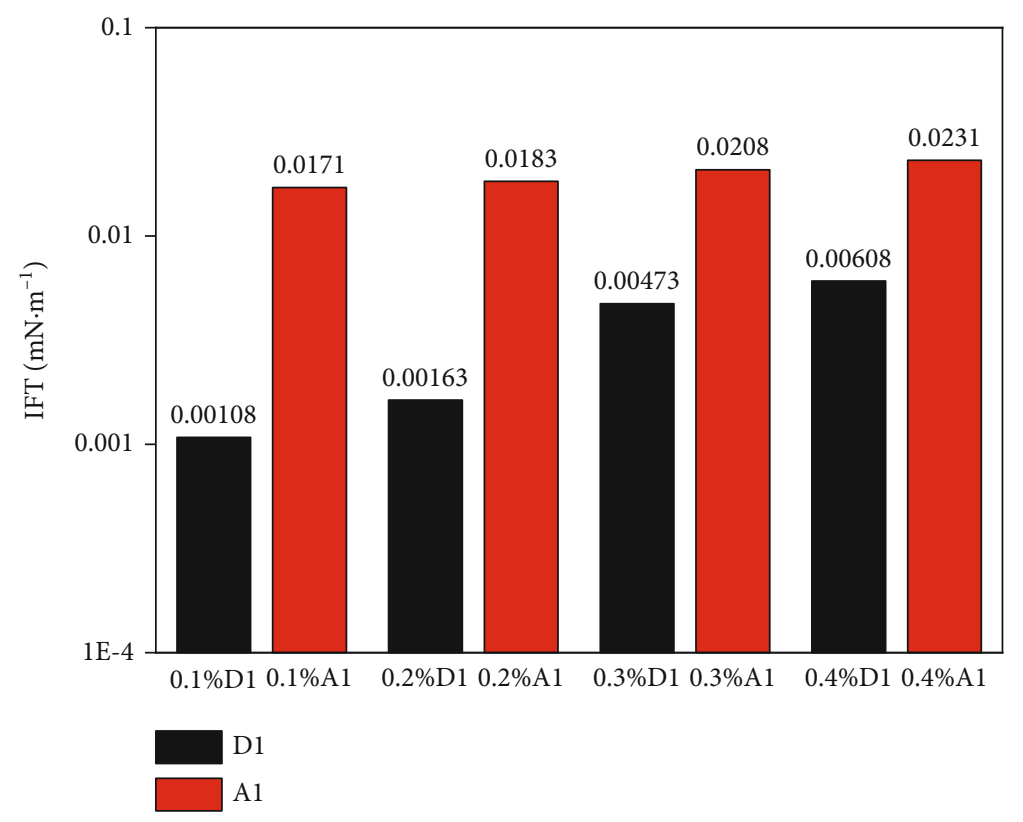

FIGURE 5: IFT between heavy oil and viscosity reducing surfactant solutions.

with simulated oil. (2) Water flooding period: water flooding was conducted until no oil was produced. (3) Chemical flooding period: then, about 10 pore volumes (PV) of chemical slugs were injected into the micromodel until no oil was produced. (4) Image analysis: at the end of water flooding and chemical flooding period, pictures were taken at different locations to analyze the oil recovery by image analysis software.

\section{Results and Discussion}

3.1. Viscosity Property. The viscosity property of polymer is crucial for the mobility control ability. Polymer solution can increase the viscosity of water phase and reduce the water-oil mobility ratio, thus improving the sweep efficiency. Figure 4 depicted the viscosity of polymer solution versus polymer concentration. As the polymer concentration increases, the viscosity of polymer solution increases. When the polymer concentration is lower than $1500 \mathrm{mg} \cdot \mathrm{L}^{-1}$, the viscosity increases slowly. When the polymer concentration is over $1500 \mathrm{mg} \cdot \mathrm{L}^{-1}$, the viscosity increases quickly. To achieve mobility control ability, the polymer concentration of PVRSF is higher than $1500 \mathrm{mg} \cdot \mathrm{L}^{-1}$.

3.2. Oil-Water Interfacial Tension Property. Surfactant can play a role in reducing interfacial tension between water and oil, which can reduce residual oil saturation trapped in porous media after water flooding. Thus, it is essential to investigate the oil-water interfacial tension property. In this study, the oil-water interfacial tension (IFT) property of viscosity reducing surfactants with different concentrations was investigated by the spinning drop method. Figure 5 depicted the IFT between heavy oil and viscosity reducing surfactant solutions. It can be clearly seen that the IFT between heavy oil and viscosity reducing surfactant $\mathrm{A} 1$ is higher than the

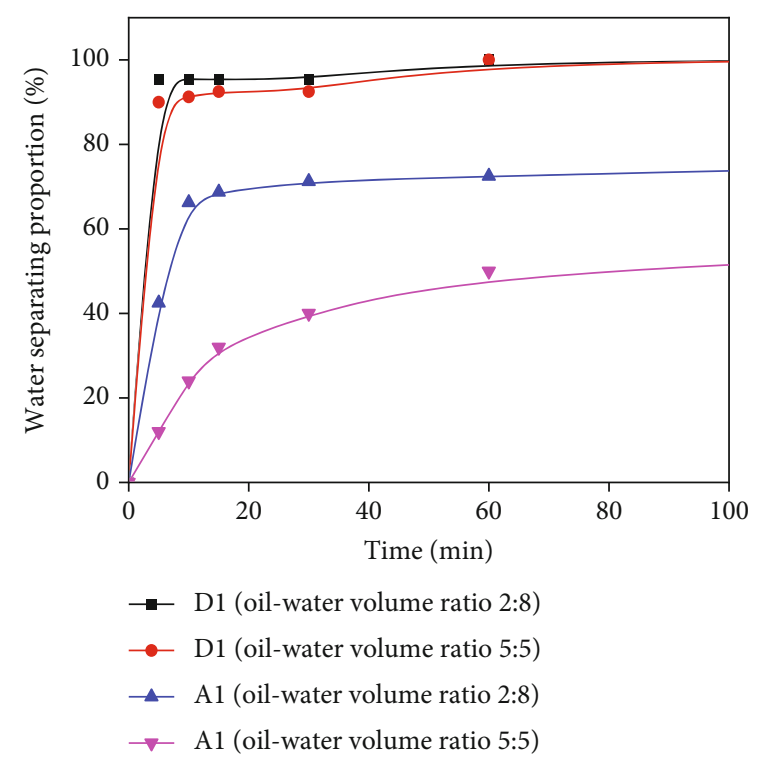

FIGURE 6: The water separating proportion of viscosity reducing surfactant $\mathrm{A} 1$ and $\mathrm{D} 1$ at different oil-water volume ratios.

IFT between heavy oil and viscosity reducing surfactant D1. For the viscosity reducing surfactant $\mathrm{A} 1$, the IFT is in the range of $1.71 \times 10^{-2}$ to $2.31 \times 10^{-2} \mathrm{mN} \cdot \mathrm{m}^{-1}$, while, for the viscosity reducing surfactant $\mathrm{D} 1$, the IFT is in the range of $1.08 \times 10^{-3}$ to $6.08 \times 10^{-3} \mathrm{mN} \cdot \mathrm{m}^{-1}$.

3.3. The Emulsifying Stability and Viscosity Reducing Ability Evaluation. Emulsifying stability and viscosity reducing ability are essential for recovering heavy oil. The surfactant can reduce the oil viscosity by forming oil-in-water emulsion. Thus, the emulsifying stability of viscosity reducing surfactants at different oil-water volume ratios was evaluated. The formed oil-in water emulsion stability can influence the 
viscosity reducing effect. The water separating proportion is used to characterize the formed emulsion stability. Figure 6 showed the water separating proportion of viscosity reducing surfactant A1 and D1 at different oil-water volume ratios.

For the viscosity reducing surfactant $\mathrm{A} 1$ and $\mathrm{D} 1$, as the time lengthens, the water separating proportion increases. The higher water separating proportion is, the worse formed emulsion stability is. As the oil-water volume ratio increases, the water separating proportion decreases. The emulsifying stability of surfactant D1 with ultralow IFT $\left(10^{-3} \mathrm{mN} / \mathrm{m}\right)$ is worse than that of surfactant $\mathrm{A} 1$ with higher IFT $\left(10^{-2} \mathrm{mN} / \mathrm{m}\right)$. For the viscosity reducing surfactant D1, the water separating proportion is higher than $90 \%$ at oil-water volume ratio of $2: 8$ and $5: 5$ after only five minutes.

Due to the bad emulsifying stability for viscosity reducing surfactant D1, the viscosity reduction rate cannot be measured. Thus, the effect of oil-water volume ratio on the viscosity reduction ability of viscosity reducing surfactant A1 was studied. The viscosity reduction ability was characterized by viscosity reduction rate. Figure 7 depicted the viscosity reduction rate of viscosity reducing surfactant $\mathrm{A} 1$ at different oil-water volume ratios. When the oil-water volume ratio is constant, as the concentration of surfactant A1 increases, the viscosity reduction rate increases. The IFT of surfactant A1 decreases slightly with the increase of surfactant concentration. When the concentration of viscosity reducing surfactant A1 is constant, as the oil-water volume ratio increases, the viscosity reduction rate decreases. Overall, the viscosity reduction rate of surfactant $\mathrm{A} 1$ with different concentrations is higher than $80 \%$ at different oil-water volume ratios. Moreover, the viscosity reduction rate of polymer/surfactant mixture was evaluated and depicted in Figure 8. The polymer concentration was $1500 \mathrm{mg} \cdot \mathrm{L}^{-1}$, and surfactant concentration was $4000 \mathrm{mg} \cdot \mathrm{L}^{-1}$. When the oil-water volume ratio is $2: 8$, although the viscosity reduction rate of polymer/surfactant mixture is lower than that of surfactant $\mathrm{A} 1$, the viscosity reduction rate is still higher than $80 \%$.

\subsection{Enhanced Oil Recovery Ability}

3.4.1. Characteristics of Flooding Curve Analysis. A series of parallel sand pack flooding experiments were conducted to investigate the enhanced oil recovery ability of polymer flooding and P-VRSF. According to the experimental method, the flooding curves of oil recovery, water cut, and injection pressure versus injected pore volume were plotted in Figure 9. The polymer concentration was $1500 \mathrm{mg} \cdot \mathrm{L}^{-1}$, and surfactant concentration was $0.4 \%$ in this study.

The flooding curves include three flooding stages: water flooding period, polymer flooding period or P-VRSF period, and subsequent water flooding period. The changing trends of flooding curves at different flooding stages are similar:

(1) During water flooding period, as the injected pore volume increases, the pressure increases firstly and then decreases to a stable value. The water cut and oil recovery increases with the increase of injected pore volume. When the injected pore is about

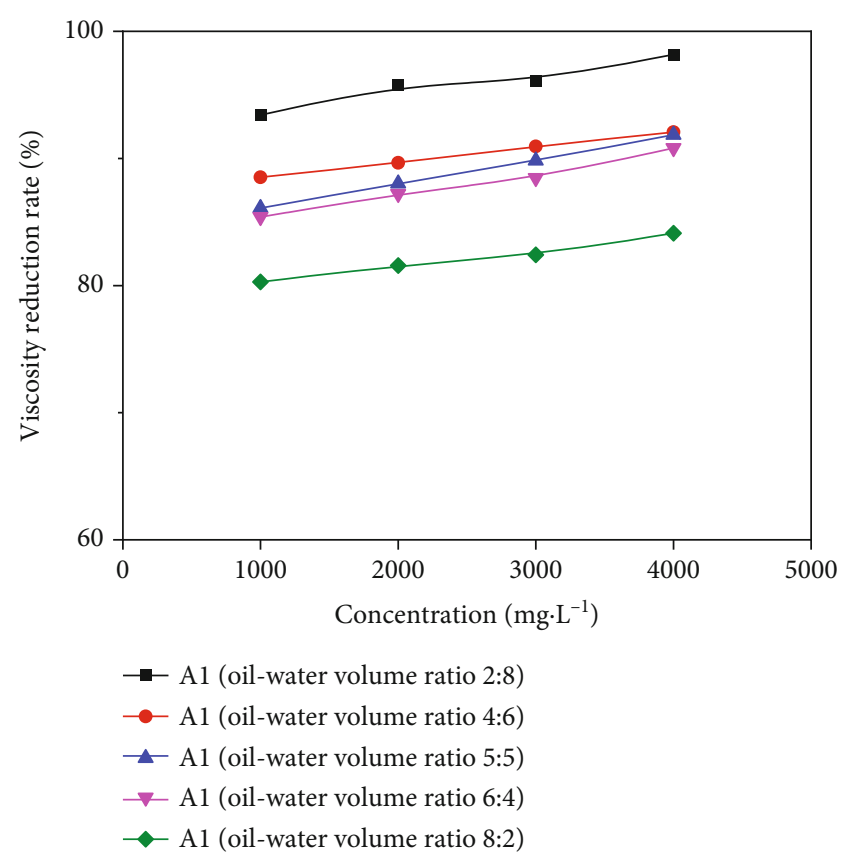

Figure 7: The viscosity reduction rate of viscosity reducing surfactant $\mathrm{A} 1$ at different oil-water volume ratios.

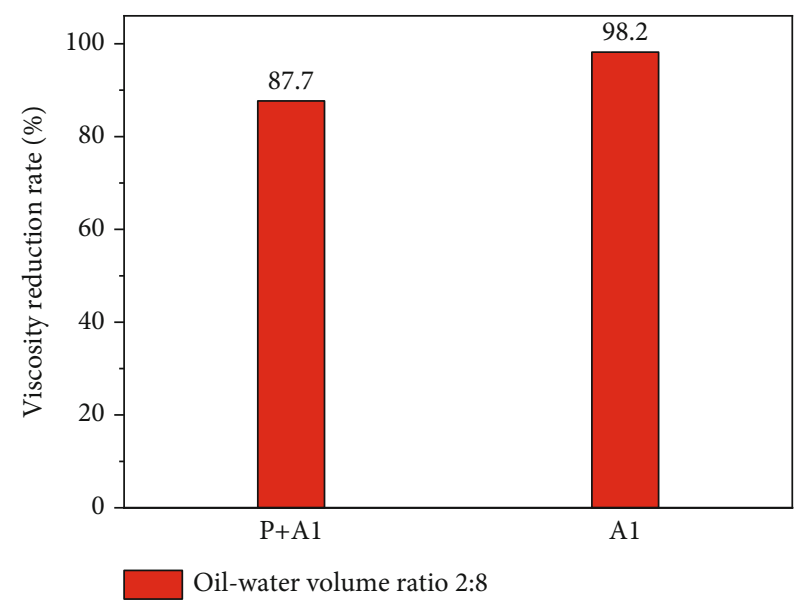

FIgURE 8: The viscosity reduction rate of surfactant $\mathrm{A} 1$ and polymer/surfactant A1 mixture.

1.2 $\mathrm{PV}$ (pore volume), the water cut reaches $95 \%$, and the oil recovery is about $37 \%$.

(2) Polymer flooding and subsequent water flooding period or P-VRSF period and subsequent water flooding period. During polymer flooding period or P-VRSF period, when the chemical slug (polymer or polymer-viscosity reducing surfactant) is injected into the sand packs, as the injection amount increases, the pressure increases and the water cut decreases. During the subsequent water flooding period, the pressure decreases and water cut increases

3.4.2. The Incremental Oil Recovery Analysis. To further reveal the differences, based on the characteristics of flooding 


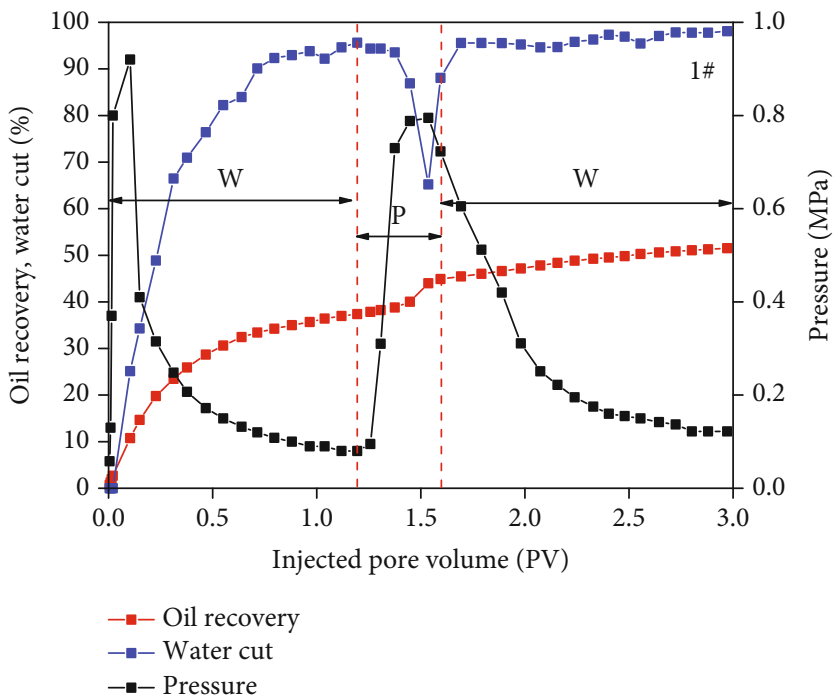

(a)

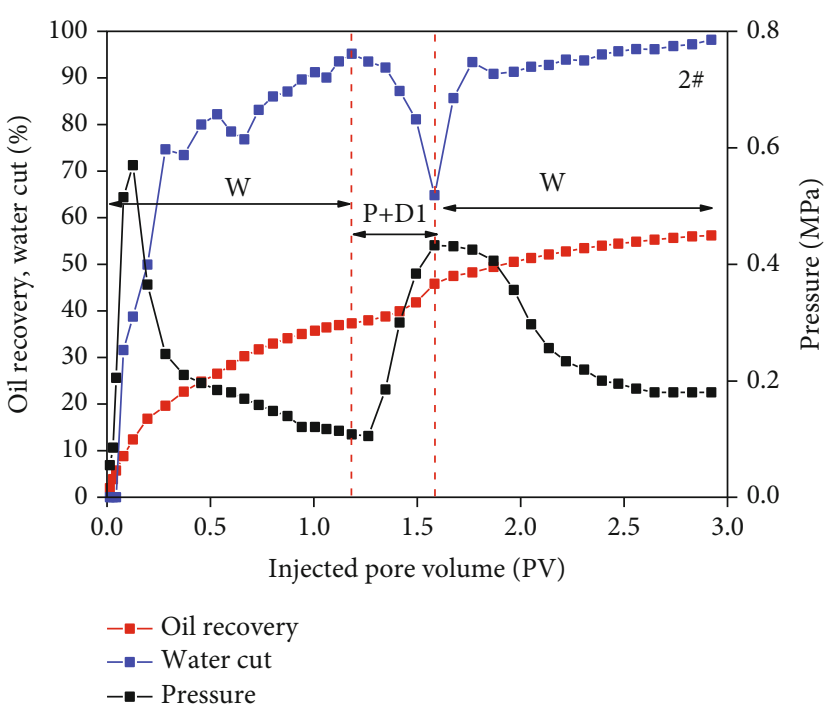

(b)

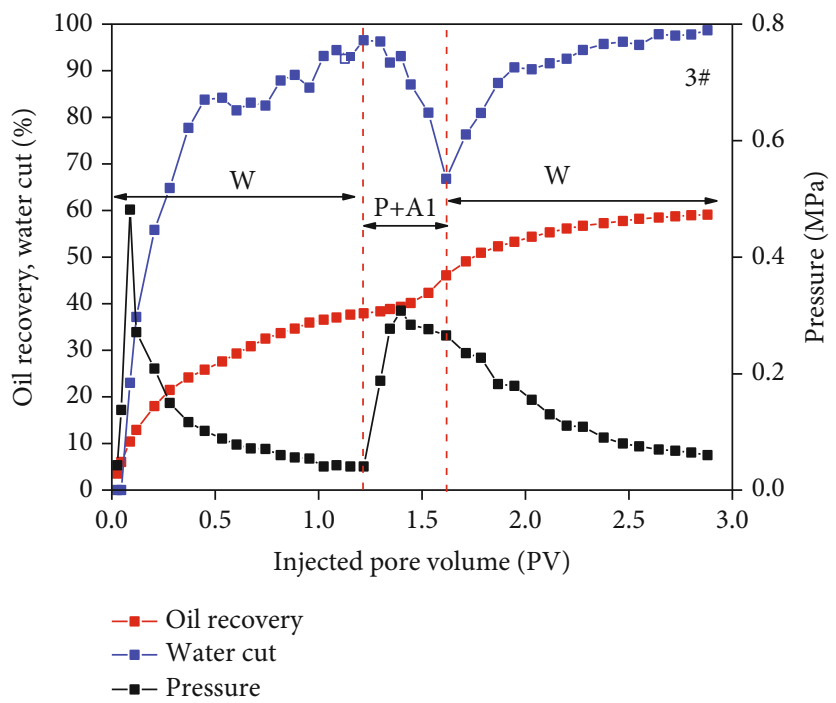

(c)

Figure 9: The oil recovery, water cut, and injection pressure versus pore volume: (a)1\#-polymer flooding; (b)2\#—polymer and D1 combination flooding; and (c)3\#-polymer and A1 combination flooding.

curves, the cumulative oil recoveries of high-permeability sand pack, low-permeability sand pack, and total sand pack at different flooding stages were depicted in Figure 10.

The change trends of cumulative oil recovery are analyzed as follows:

(1) During the initial water flooding period, due to the permeability differences between the high- and lowpermeability sand packs, as the injected volumes increase, most of injection water enters through the high-permeability sand pack, resulting in higher oil recovery in high-permeability sand pack

(2) During chemical flooding and subsequent water flooding period, as the chemical slugs are injected, due to the mobility control ability, the polymer solution can increase the viscosity of injection water. The viscosity reducing surfactant can reduce the crude oil viscosity. The sweep efficiency can be improved, which increases the water intake volume of lowpermeability sand pack and recover the remaining oil in low-permeability sand pack

Thus, the incremental oil recovery of polymer flooding and P-VRSF was summarized in Table 3 and depicted in Figure 11.

It can be clearly seen that the total incremental oil recovery of P-VRSF is higher than that of polymer flooding. Moreover, polymer-viscosity reducing surfactant $\mathrm{A} 1$ with higher IFT can have higher incremental oil recovery. The viscosity reducing surfactant $\mathrm{A} 1$ with higher IFT can have better emulsifying stability, which can reduce the crude oil viscosity and have better sweep efficiency improvement ability. It indicates that more chemical slugs are diverted into the low- 


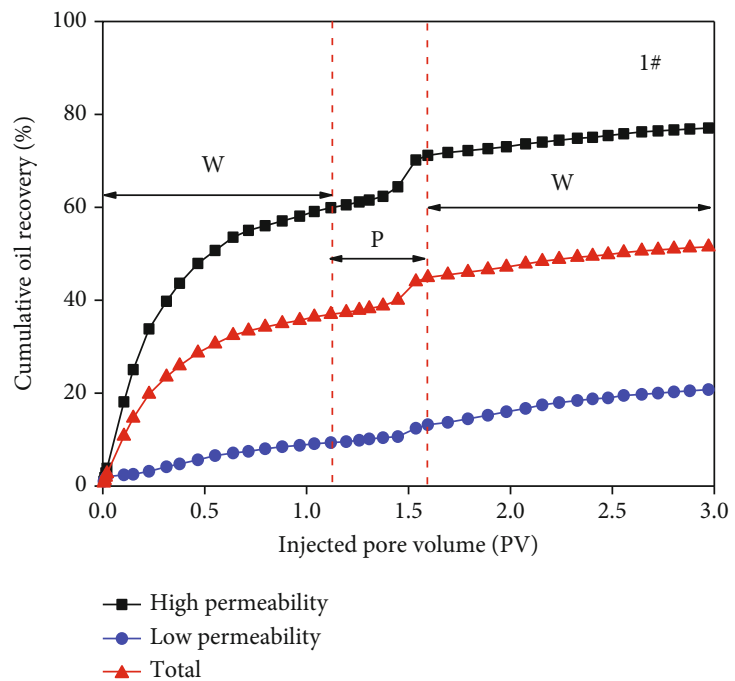

(a)

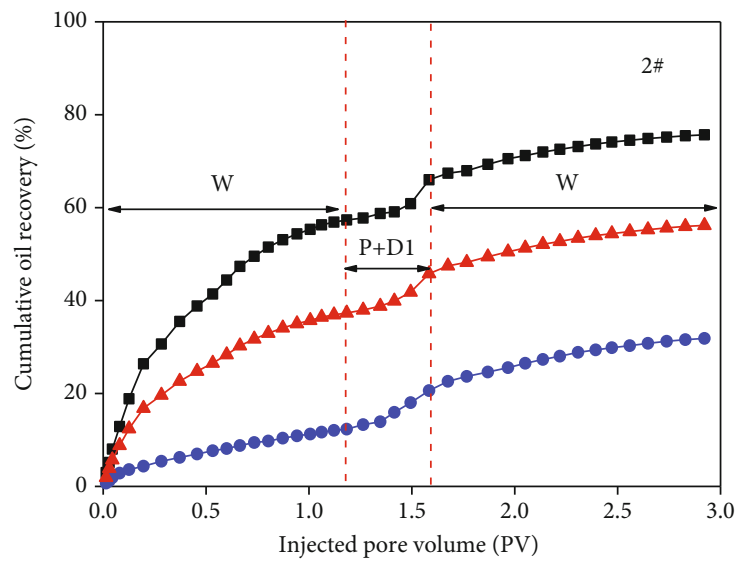

$\rightarrow-$ High permeability

—- Low permeability

- Total

(b)

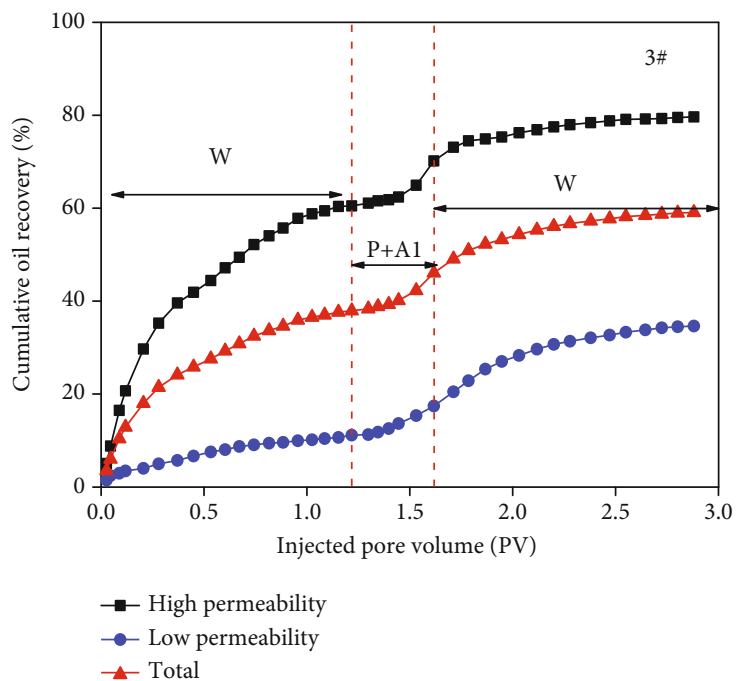

(c)

FIGURE 10: The cumulative oil recovery versus pore volumes injected: (a)1\#-polymer flooding; (b)2\#—polymer and D1 combination flooding; and (c)3\#-polymer and A1 combination flooding. 
TABLE 3: The incremental oil recovery results of polymer flooding and polymer-viscosity reducing surfactant flooding.

\begin{tabular}{|c|c|c|c|c|}
\hline Chemical slug & Sand packs & Water flooding recovery (\%) & $\begin{array}{l}\text { Chemical flooding and subsequent } \\
\text { water flooding recovery }(\%)\end{array}$ & Incremental oil recovery (\%) \\
\hline \multirow{3}{*}{$0.15 \% \mathrm{P}$} & High permeability & 60.5 & 77.0 & 16.5 \\
\hline & Low permeability & 9.6 & 20.8 & 11.2 \\
\hline & Total & 37.4 & 51.5 & 14.1 \\
\hline \multirow{3}{*}{$0.15 \% \mathrm{P}+0.4 \% \mathrm{D} 1$} & High permeability & 57.3 & 75.7 & 18.4 \\
\hline & Low permeability & 12.3 & 31.8 & 19.5 \\
\hline & Total & 37.3 & 56.2 & 18.9 \\
\hline \multirow{3}{*}{$0.15 \% \mathrm{P}+0.4 \% \mathrm{~A} 1$} & High permeability & 60.5 & 79.6 & 19.1 \\
\hline & Low permeability & 11.2 & 34.7 & 23.5 \\
\hline & Total & 37.9 & 59.1 & 21.2 \\
\hline
\end{tabular}

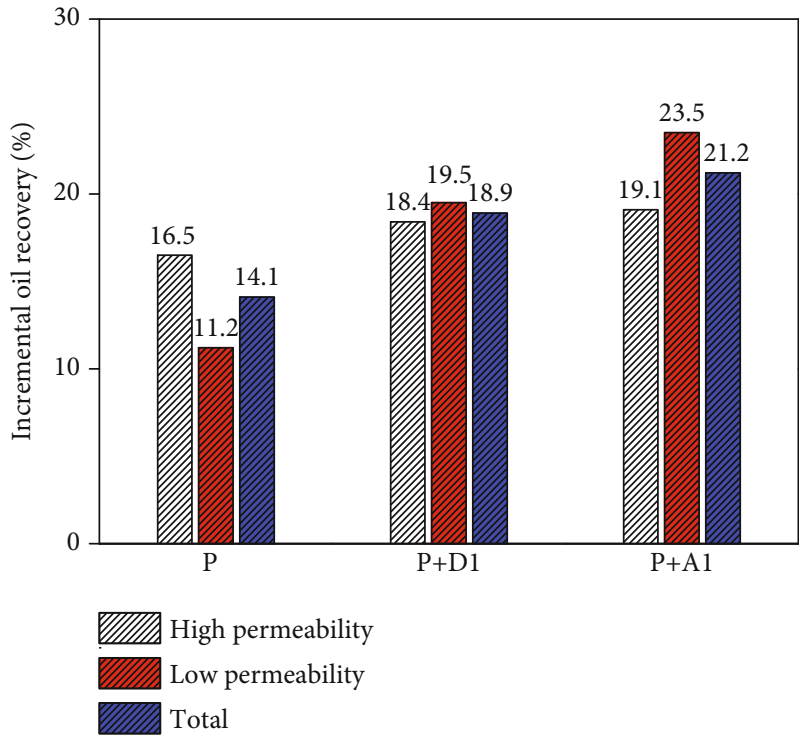

FIGURE 11: The incremental oil recovery results of polymer flooding and polymer-viscosity reducing surfactant flooding.

permeability sand pack and more remaining oil in lowpermeability sand pack can be recovered.

3.5. 2D Glass-Etched Micromodel Flooding Results. To further clarify the EOR mechanism of P-VRSF, the 2D glass-etched micromodel flooding experiments were conducted to investigate the remaining oil mobilization process in pore-scale level. According to the distribution characteristics of the remaining oil, the incremental oil recovery was analyzed by image analysis software.

3.5.1. The Remaining Oil Distribution Analysis. Figure 12 showed the remaining oil distribution at the end of water flooding and polymer-viscosity reducing surfactant flooding.

It can be seen that the remaining oil distribution at the end of water flooding is similar, while the remaining oil distribution at the end of polymer flooding, polymer and D1 combination flooding, and polymer and A1 combination flooding are obviously different.
During the water flooding period, due to the adverse mobility ratio between water and oil, the viscous fingering phenomenon can be observed and the injected water will flow through the main streamline of the injection end and production end, resulting in forming a similar swept area.

During the polymer flooding, P-VRSF period, most of injected polymer solution, P-VRSF system still flows through the formed water path and displace the residual oil after water flooding. Moreover, for the polymer that can increase the viscosity of injection water and the viscosity reducing surfactant can decrease the viscosity of crude oil, the flow resistance increases, and the swept area increases. It can be seen clearly that the swept area of polymerviscosity reducing surfactant combination flooding is higher than that of polymer flooding. Moreover, the swept area of polymer and A1 combination flooding is higher than that of polymer and D1 combination flooding. The results indicate that the viscosity reducing surfactant A1 with good emulsion stability can have better sweep efficiency than the viscosity reducing surfactant D1 with ultralow interfacial tension.

3.5.2. The Incremental Oil Recovery Analysis. The micromodel flooding experiments include water flooding and chemical flooding stages. Based on the above remaining oil distribution qualitative analysis, the image processing software ImageJ is used to calculate the oil recovery at different flooding stages. Then, the incremental oil recovery can be calculated. Table 4 and Figure 13 showed the oil recovery at different flooding stages.

The micromodel flooding results show that the water flooding recovery is in the range of $35.31 \%$ to $36.46 \%$. The chemical flooding recovery is in the range of $50.67 \%$ to $58.29 \%$. The incremental oil recovery is in the range of $15.36 \%$ to $21.83 \%$. The incremental oil recovery of polymer and surfactant A1 combination flooding is the highest, the second is the polymer and surfactant D1 combination flooding, and the polymer flooding is the least. The polymer and A1 combination flooding can have better improve sweep efficiency than the polymer flooding and polymer and D1 combination flooding. 


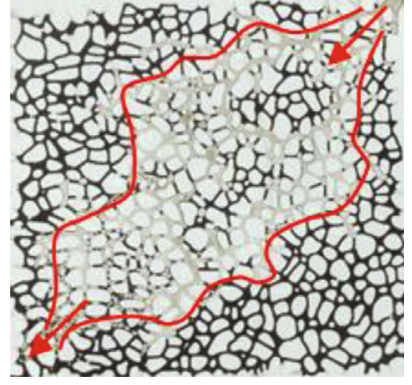

(a) Water flooding

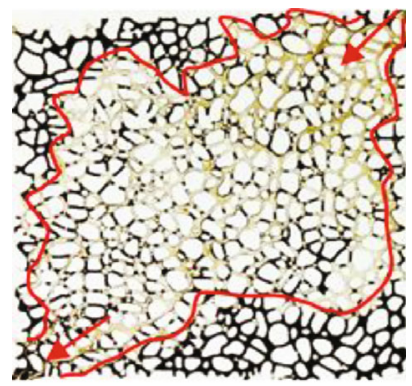

(d) Polymer and D1 combination flooding

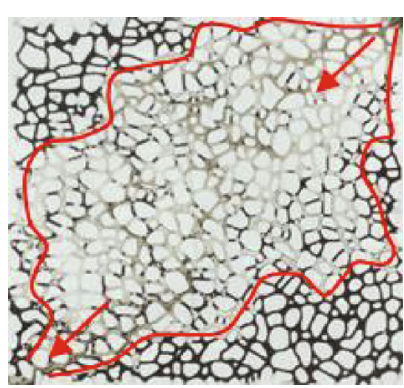

(b) Polymer flooding

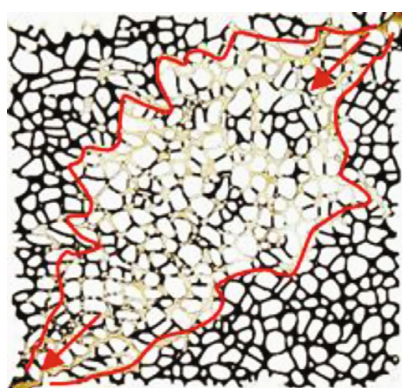

(e) Water flooding

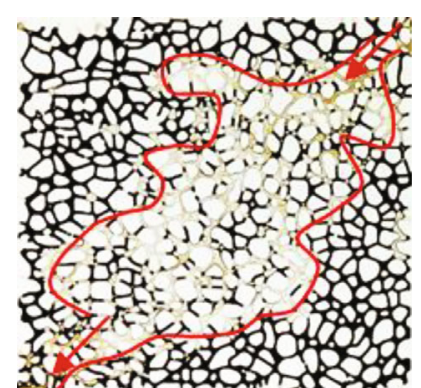

(c) Water flooding

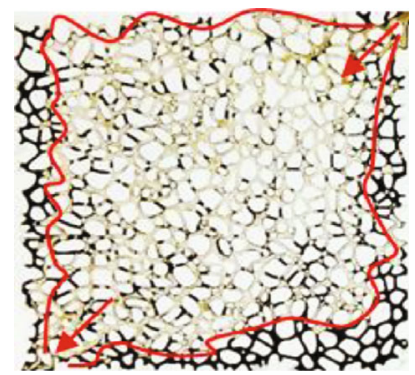

(f) Polymer and Al combination flooding

Figure 12: The remaining oil distribution at the end of water flooding and polymer-viscosity reducing surfactant combination flooding.

TABLE 4: The incremental oil recovery results at different flooding stages for micromodel flooding.

\begin{tabular}{lccc}
\hline $\begin{array}{l}\text { Chemical } \\
\text { slug }\end{array}$ & $\begin{array}{c}\text { Water flooding } \\
\text { recovery (\%) }\end{array}$ & $\begin{array}{c}\text { Chemical flooding } \\
\text { recovery }(\%)\end{array}$ & $\begin{array}{c}\text { Incremental oil } \\
\text { recovery/\% }\end{array}$ \\
\hline P & 35.31 & 50.67 & 15.36 \\
P+D1 & 35.66 & 52.89 & 17.23 \\
P+A1 & 36.46 & 58.29 & 21.83 \\
\hline
\end{tabular}

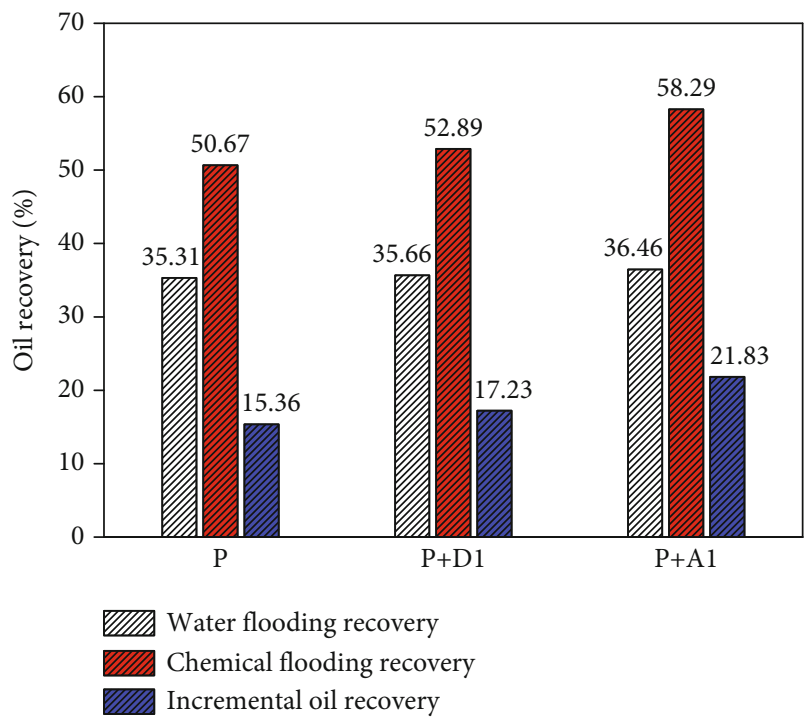

Figure 13: The incremental oil recovery results at different flooding stages for micromodel flooding.

\section{Conclusions}

In this study, the polymer-viscosity reducing surfactant combination flooding system was proposed to enhance oil recovery in conventional heavy oil reservoir. Firstly, the viscosity property, oil-water interfacial tension property, and oil viscosity reduction property were investigated. Then, a series of parallel sand pack and 2D glass-etched micromodel flooding experiments were conducted to investigate the enhanced oil recovery (EOR) ability and mechanism in pore level. Some remarking conclusions can be obtained as follows:

(1) Polymer solution can increase the viscosity of water phase and reduce the water-oil mobility ratio, thus improving the sweep efficiency. To achieve mobility control ability, the polymer concentration of polymer-viscosity reducing surfactant combination flooding is higher than $1500 \mathrm{mg} \cdot \mathrm{L}^{-1}$

(2) The IFT of viscosity reducing surfactant A1 is in the range of $1.71 \times 10^{-2}$ to $2.31 \times 10^{-2} \mathrm{mN} \cdot \mathrm{m}^{-1}$. The IFT of viscosity reducing surfactant D1 is in the range of $1.08 \times 10^{-3}$ to $6.08 \times 10^{-3} \mathrm{mN} \cdot \mathrm{m}^{-1}$. The emulsifying stability of surfactant D1 with ultralow IFT $\left(10^{-3} \mathrm{mN} / \mathrm{m}\right)$ is worse than that of surfactant A1 with higher IFT $\left(10^{-2} \mathrm{mN} / \mathrm{m}\right)$. The viscosity reduction rate of surfactant $\mathrm{A} 1$ with higher IFT was higher than $80 \%$ at different oil-water volume ratios

(3) The parallel sand pack flooding results show that the total incremental oil recovery of P-VRSF is higher than that of polymer flooding. Moreover, polymersurfactant Al with higher IFT can have higher 
incremental oil recovery, which was attributed to the better emulsifying stability of A1 to reduce the crude oil viscosity and improve sweep efficiency

(4) The $2 \mathrm{D}$ micromodel flooding results show that the swept area of polymer flooding and polymerviscosity reducing surfactant is larger than that of water flooding. Moreover, the swept area of surfactant with good emulsifying stability is larger than that of surfactant with ultralow IFT. The incremental oil recovery of polymer and surfactant A1 combination flooding is the highest, the second is the polymer and surfactant D1 combination flooding, and the polymer flooding is the least

\section{Data Availability}

All data used to support the findings of this study are available from the corresponding authors on request.

\section{Conflicts of Interest}

The authors declare that they have no conflicts of interest.

\section{Acknowledgments}

This work was supported by the National Natural Science Foundation of China (project number: 51604037) and Research Institute of Exploration and Development of Shengli Oilfield.

\section{References}

[1] A. Mai, J. Bryan, N. Goodarzi, and A. Kantzas, "Insights into non-thermal recovery of heavy oil," Journal of Canadian Petroleum Technology, vol. 48, no. 3, pp. 27-35, 2009.

[2] T. Babadagli, V. Er, K. Naderi, Z. Burkus, and B. Ozum, "Use of biodiesel as an additive in thermal recovery of heavy oil and bitumen," Journal of Canadian Petroleum Technology, vol. 49, no. 11, pp. 43-48, 2010.

[3] V. Alvarado and E. Manrique, "Enhanced oil recovery: an update review,” Energies, vol. 3, no. 9, pp. 1529-1575, 2010.

[4] B. Su and Y. Fujimitsu, "Research on heavy oil thermal recovery by $\mathrm{CO} 2$ steam flooding with help of combination of borehole-surface electric potential and cross-borehole electric potential," Energy Exploration \& Exploitation, vol. 29, no. 6, pp. 797-815, 2011.

[5] T. Babadagli and B. Ozum, "BioDiesel as additive in high pressure and temperature steam recovery of heavy oil and bitumen," Oil and Gas Science and Technology - Revue d'IFP Energies Nouvelles, vol. 67, no. 3, pp. 413-421, 2012.

[6] M. M. Salehi, E. Sahraei, S. Alireza, and T. Nejad, "Experimental study of new improved oil recovery from heavy and semiheavy oil reservoirs by implementing immiscible heated surfactant alternating gas injection," Journal of Petroleum and Gas Engineering, vol. 4, no. 6, pp. 154-159, 2013.

[7] F. Bordeaux Rego, V. E. Botechia, and D. J. Schiozer, "Heavy oil recovery by polymer flooding and hot water injection using numerical simulation," Journal of Petroleum Science and Engineering, vol. 153, pp. 187-196, 2017.
[8] R. Coelho, C. Ovalles, I. P. Benson, and B. Hascakir, "Effect of clay presence and solvent dose on hybrid solvent--steam performance," Journal of Petroleum Science and Engineering, vol. 150, pp. 203-207, 2017.

[9] A. Askarova, A. Turakhanov, S. Markovic et al., "Thermal enhanced oil recovery in deep heavy oil carbonates: experimental and numerical study on a hot water injection performance," Journal of Petroleum Science and Engineering, vol. 194, article 107456, 2020.

[10] T. Al-Ghailani, Y. M. Al-Wahaibi, S. J. Joshi, S. N. Al-Bahry, A. E. Elshafie, and A. S. Al-Bemani, "Application of a new bio-ASP for enhancement of oil recovery: mechanism study and core displacement test," Fuel, vol. 287, article 119432, 2021.

[11] M. Al-Gosayir, T. Babadagli, and J. Leung, "Optimization of SAGD and solvent additive SAGD applications: comparative analysis of optimization techniques with improved algorithm configuration," Journal of Petroleum Science and Engineering, vol. 98, pp. 61-68, 2012.

[12] F. J. Argüelles-Vivas, T. Babadagli, L. Little, N. Romaniuk, and B. Ozum, "High temperature density, viscosity, and interfacial tension measurements of bitumen-pentane-biodiesel and process water mixtures," Journal of Chemical and Engineering Data, vol. 57, no. 10, pp. 2878-2889, 2012.

[13] R. Deschamps, N. Guy, C. Preux, and O. Lerat, "Analysis of heavy oil recovery by thermal EOR in a meander belt: from geological to reservoir modeling," Oil and Gas Science and Technology - Revue d'IFP Energies Nouvelles, vol. 67, no. 6, pp. 999-1018, 2012.

[14] D. Wang, R. S. Seright, Z. Shao, and J. Wang, "Key aspects of project design for polymer flooding at the Daqing oilfield," SPE Reservoir Evaluation and Engineering, vol. 11, no. 6, pp. 1117-1124, 2008.

[15] K. Rai, R. T. Johns, M. Delshad, L. W. Lake, and A. Goudarzi, "Oil-recovery predictions for surfactant polymer flooding," Journal of Petroleum Science and Engineering, vol. 112, pp. 341-350, 2013.

[16] B. Shaker Shiran and A. Skauge, "Enhanced oil recovery (EOR) by combined low salinity water/polymer flooding," Energy and Fuels, vol. 27, no. 3, pp. 1223-1235, 2013.

[17] M. Abdulbaki, C. Huh, K. Sepehrnoori, M. Delshad, and A. Varavei, "A critical review on use of polymer microgels for conformance control purposes," Journal of Petroleum Science and Engineering, vol. 122, pp. 741-753, 2014.

[18] R. N. Manichand and R. Seright, "Field vs. "laboratory polymer-retention values for a polymer flood in the Tambaredjo Field"," SPE Reservoir Evaluation \& Engineering, vol. 7, pp. 314-325, 2014.

[19] A. M. AlSofi and M. J. Blunt, "Polymer flooding design and optimization under economic uncertainty," Journal of Petroleum Science and Engineering, vol. 124, pp. 46-59, 2014.

[20] J. J. Sheng, B. Leonhardt, and N. Azri, "Status of polymerflooding technology," Journal of Canadian Petroleum Technology, vol. 54, no. 2, pp. 116-126, 2015.

[21] M. S. Kamal, A. S. Sultan, U. A. Al-Mubaiyedh, and I. A. Hussein, "Review on polymer flooding: rheology, adsorption, stability, and field applications of various polymer systems," Polymer Reviews, vol. 55, no. 3, pp. 491-530, 2015.

[22] S. Zhu, L. Shi, X. Wang, C. Liu, X. Xue, and Z. Ye, "Investigation into Mobility Control Mechanisms by Polymer Flooding in Offshore High-Permeable Heavy Oil Reservoir," Energy 
Sources Part A-Recovery Utilization and Environmental Effects, pp. 1-14, 2020.

[23] H. Saboorian-Jooybari, M. Dejam, and Z. Chen, "Heavy oil polymer flooding from laboratory core floods to pilot tests and field applications: half-century studies," Journal of Petroleum Science and Engineering, vol. 142, pp. 85-100, 2016.

[24] E. Amirian, M. Dejam, and Z. Chen, "Performance forecasting for polymer flooding in heavy oil reservoirs," Fuel, vol. 216, pp. 83-100, 2018.

[25] Z. Jeirani, B. M. Jan, B. S. Ali, C. H. See, and W. Saphanuchart, "Pre-prepared microemulsion flooding in enhanced oil recovery: a review," Petroleum Science and Technology, vol. 32, no. 2, pp. 180-193, 2014.

[26] J. Prasanphanich, M. H. Kalaei, M. Delshad, and K. Sepehrnoori, "Chemical flooding optimisation using the experimental design approach and response surface methodology," International Journal of Oil, Gas and Coal Technology, vol. 5, no. 4, pp. 368-384, 2012.

[27] A. Kamari, F. Gharagheizi, A. Shokrollahi, M. Arabloo, and A. H. Mohammadi, "Integrating a robust model for predicting surfactant-polymer flooding performance," Journal of Petroleum Science and Engineering, vol. 137, pp. 87-96, 2016.

[28] A. A. Dehghan, A. Jadaly, S. Ayatollahi, and M. Masihi, "Acidic heavy oil recovery using a new formulated surfactant accompanying alkali-polymer in high salinity brines," Journal of Surfactants and Detergents, vol. 20, no. 3, pp. 725-733, 2017.

[29] H. Sharma, K. Panthi, and K. K. Mohanty, "Surfactant-less alkali-cosolvent-polymer floods for an acidic crude oil," Fuel, vol. 215, pp. 484-491, 2018.

[30] Y. Ma, J. Hou, F. Zhao, and Z. Song, "Linearly descending viscosity for alkaline-surfactant-polymer flooding mobility modification in multilayer heterogeneous reservoirs," RSC Advances, vol. 8, no. 15, pp. 8269-8284, 2018.

[31] N. Pal, N. Saxena, and A. Mandal, "Characterization of alkalisurfactant-polymer slugs using synthesized Gemini surfactant for potential application in enhanced oil recovery," Journal of Petroleum Science and Engineering, vol. 168, pp. 283-300, 2018.

[32] S. Aramideh, R. Borgohain, P. K. Naik, C. T. Johnston, P. P. Vlachos, and A. M. Ardekani, "Multi-objective history matching of surfactant-polymer flooding," Fuel, vol. 228, pp. 418428, 2018.

[33] P. Druetta and F. Picchioni, "Surfactant-polymer flooding: influence of the injection scheme," Energy and fuels, vol. 32, no. 12, pp. 12231-12246, 2018.

[34] R. Farajzadeh, A. Ameri, M. J. Faber, D. W. van Batenburg, D. M. Boersma, and J. Bruining, "Effect of continuous, trapped, and flowing gas on performance of alkaline surfactant polymer (ASP) flooding," Industrial \& Engineering Chemistry Research, vol. 52, no. 38, pp. 13839-13848, 2013.

[35] A. Aitkulov and K. K. Mohanty, "Investigation of alkalinesurfactant-polymer flooding in a quarter five-spot sandpack for viscous oil recovery," Journal of Petroleum Science and Engineering, vol. 175, pp. 706-718, 2019.

[36] A. Davarpanah and B. Mirshekari, "Numerical simulation and laboratory evaluation of alkali-surfactant-polymer and foam flooding," International journal of Environmental Science and Technology, vol. 17, no. 2, pp. 1123-1136, 2020.

[37] O. S. Alade, D. al Shehri, M. Mahmoud et al., "A novel technique for heavy oil recovery using poly vinyl alcohol (PVA) and PVA-NaOH with ethanol additive," Fuel, vol. 285, p. 119128, 2021.
[38] D. Xie, J. Hou, A. Doda, and J. Trivedi, “Application of organic alkali for heavy-oil Enhanced Oil Recovery (EOR), in comparison with inorganic alkali," Energy \& Fuels, vol. 30, no. 6, pp. 4583-4595, 2016.

[39] R. Kharrat and B. Y. Jamaloei, "Analysis of pore-level phenomena of dilute surfactant flooding in the presence and absence of connatewater saturation," Journal of Porous Media, vol. 13, pp. 671-690, 2010.

[40] G. Hirasaki, C. A. Miller, and M. Puerto, "Recent advances in surfactant EOR,” SPE Journal, vol. 16, no. 4, pp. 889-907, 2011.

[41] A. Kianinejad, M. H. Ghazanfari, R. Kharrat, and D. Rashtchian, "An experimental investigation of surfactant flooding as a good candidate for enhancing oil recovery from fractured reservoirs using one-quarter five spot micromodels: the role of fracture geometrical properties," Energy Sources Part A-Recovery Utilization and Environmental Effects, vol. 35, no. 20, pp. 1929-1938, 2013.

[42] K. M. Ko, B. H. Chon, S. B. Jang, and H. Y. Jang, "Surfactant flooding characteristics of dodecyl alkyl sulfate for enhanced oil recovery," Journal of Industrial and Engineering Chemistry, vol. 20, no. 1, pp. 228-233, 2014.

[43] S. Morshedi, S. Foroughi, and M. S. Beiranvand, "Numerical simulation of surfactant flooding in Darcy scale flow," Petroleum Science and Technology, vol. 32, no. 11, pp. 1365-1374, 2014.

[44] M. S. Kamal, S. M. Shakil Hussain, and A. S. Sultan, "Development of novel amidosulfobetaine surfactant-polymer systems for EOR applications," Journal of Surfactants and Detergents, vol. 19, no. 5, pp. 989-997, 2016.

[45] M. A. Ahmadi and S. R. Shadizadeh, "Nano-surfactant flooding in carbonate reservoirs: a mechanistic study," European Physical Journal Plus, vol. 132, no. 6, p. 246, 2017.

[46] H. Sajjad Rabbani, Y. Osman, I. Almaghrabi, M. Azizur Rahman, and T. Seers, "The control of apparent wettability on the efficiency of surfactant flooding in tight carbonate rocks," Processes, vol. 7, no. 10, p. 684, 2019.

[47] S. Mahmoudi, A. Jafari, and S. Javadian, "Temperature effect on performance of nanoparticle/surfactant flooding in enhanced heavy oil recovery," Petroleum Science, vol. 16, no. 6, pp. 1387-1402, 2019.

[48] L. Mejia, M. Tagavifar, K. Xu, M. Mejia, Y. Du, and M. Balhoff, "Surfactant flooding in oil-wet micromodels with high permeability fractures," Fuel, vol. 241, pp. 1117-1128, 2019.

[49] Y. A. Alzahid, P. Mostaghimi, S. D. C. Walsh, and R. T. Armstrong, "Flow regimes during surfactant flooding: the influence of phase behaviour," Fuel, vol. 236, pp. 851-860, 2019.

[50] A. H. Abbas, W. R. W. Sulaiman, M. Z. Jaafar, A. O. Gbadamosi, S. S. Ebrahimi, and A. Elrufai, "Numerical study for continuous surfactant flooding considering adsorption in heterogeneous reservoir," Journal of King Saud University: Engineering Sciences, vol. 32, no. 1, pp. 91-99, 2020. 